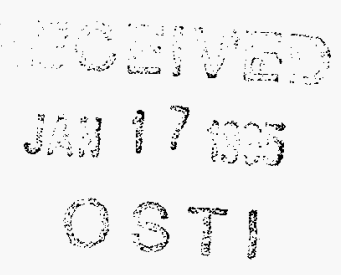

\title{
DISRUPTIONS, LOADS, AND DYNAMIC RESPONSE OF ITER
}

\author{
B. Nelson, B. Riemer, R. Sayer, and D. Strickler \\ Oak Ridge National Laboratory, Oak Ridge, TN 37831 \\ P. Barabaschi, K. Ioki, G. Johnson, K. Shimizu, and D. Williamson \\ ITER Joint Central Team
}

\begin{abstract}
The submitted manuscript has been
authored by a contrector of the U.S. Government under contrict No. OFAC05-840R2 1400. Accordingty, the U.S. Government retsins roverty-trent rateins in nonoxclusive. reyty-tres kicenso to pubish or recroduce the oublished form of this contribution. or sllow others to do so. for U.S. Government
purposes."
\end{abstract}

Presented at the 16th IEEE/NPSS Symposium on Fusion Engineering Champaign, Illinois

September 30 to October 5, 1995

DISCLAIMER

This report was prepared as an account of work sponsored by an agency of the United States Government. Neither the United States Government nor any agency thereof, nor any of their employees, makes any warranty, express or implied, or assumes any legal liability or responsibility for the accuracy, completeness, or usefulness of any information, apparatus, product, or process disclosed, or represents that its use would not infringe privately owned rights. Reference herein to any specific commercial product, process, or service by trade name, trademark, manufacturer, or otherwise does not necessarily constitute or imply its endorsement, recommendation, or favoring by the United States Government or any agency thereof. The views and opinions of authors expressed herein do not necessarily state or reflect those of the United States Government or any agency thereof. 


\title{
DISRUPTIONS, LOADS, AND DYNAMIC RESPONSE OF ITER
}

\author{
B. Nelson, ${ }^{*}$ B. Riemer, ${ }^{*}$ R. Sayer, ${ }^{*}$ and D. Strickler ${ }^{*}$ \\ Oak Ridge National Laboratory, Oak Ridge, TN 37831
P. Barabaschi, K. Ioki, G. Johnson, K. Shimizu, and D. Williamson
ITER Joint Central Team

\begin{abstract}
Plasma disruptions and the resulting electromagnetic loads are critical to the design of the vacuum vessel and in-vessel components of the International Thermonuclear Experimental Reactor (ITER). This paper describes the status of plasma disruption simulations and related analysis, including the dynamic response of the vacuum vessel and in-vessel components, stresses and deflections in the vacuum vessel, and reaction loads in the support structures.
\end{abstract}

\section{INTRODUCTION AND BASIS OF ANALYSIS}

The problem of determining the effect of disruptions on the International Thermonuclear Experimental Reactor (ITER) components must be solved by simulating various types of plasma disruptions, calculating the induced currents and loads in the conducting structures, and then calculating the dynamic mechanical response. Design details, such as geometry, electrical connections, wall thickness, and support stiffnesses, affect the response of the system and must be included in the calculations in a self-consistent way.

The ITER vacuum vessel and in-vessel component arrangement are shown in Fig. 1 and described in detail in $[1,2]$. The

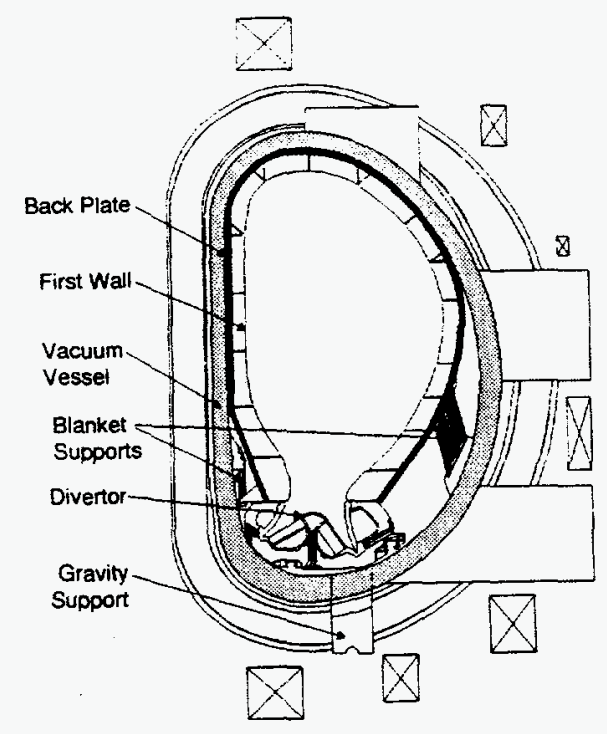

Fig. 1 ITER geometry and general arrangement.

\footnotetext{
* Research sponsored by the Office of Fusion Energy, U.S. Department of Energy, under contract DE-AC05-840R21400 with Lockheed Martin Energy Systems, Inc.
}

vacuum vessel is a critical component because it provides the primary safety barrier and must withstand large electromagnetic loads and overpressure without losing its containment function. The $316 \mathrm{LN}$ double-wall structure, filled with water and nonstructural stainless steel plates, is designed to provide the necessary strength, nuclear shielding, and electrical resistance in a relatively simple structure. The blanket and shield assembly consists of 720 individual modules attached to a toroidally continuous backplate. This assembly is structurally independent from the vacuum vessel except for vertical support, which is provided by 40 inboard and 40 outboard supports. The divertor consists of 60 toroidally independent cassettes supported by rails to the vacuum vessel.

\section{LOADING CONDITIONS AND DISRUPTION SIMULATIONS}

The vacuum vessel and in-vessel components must withstand loads due to gravity, temperature gradients, internal and external overpressure, coil faults, earthquakes, and plasma disruptions. The loading conditions for the vacuum vessel are combined and classified as listed in Table I. All loads are essentially static and symmetric except for the disruption and seismic loads. Component stresses are compared to design criteria depending on the classification of the loading condition [3]. Stresses from normal and upset loads must not

Table I

Vacuum Vessel Loading Conditions

\begin{tabular}{|c|c|c|}
\hline Load condition & $\begin{array}{c}\text { Range of } \\
\text { values }\end{array}$ & $\begin{array}{c}\text { Design } \\
\text { criteria } \\
\text { level }\end{array}$ \\
\hline \multicolumn{3}{|l|}{ Normal operation } \\
\hline $\begin{array}{l}\text { Gravity, MN (vessel + blanket + } \\
\text { divertor) }\end{array}$ & 165 & $\mathbf{A}$ \\
\hline Coolant pressure, $\mathrm{MPz}$ & $0-2.2$ & A \\
\hline $\begin{array}{l}\text { Temperature gradients from nuclear } \\
\text { heating, }{ }^{\circ} \mathrm{C}\end{array}$ & -5 & $\mathbf{A}$ \\
\hline $\begin{array}{l}\text { Temperature difference between } \\
\text { vacuum vessel and blanket and shield } \\
\text { assembly, }{ }^{\circ} \mathrm{C}\end{array}$ & $0-150$ & A \\
\hline \multicolumn{3}{|l|}{ Plasma disruptions (including VDE) } \\
\hline Direatly applied pressure, $\mathrm{MPa}$ & \pm 0.3 & $\mathbf{A}$ \\
\hline $\begin{array}{l}\text { Reacted loads, MN (from in-vessel } \\
\text { components) }\end{array}$ & -150 & A \\
\hline \multicolumn{3}{|l|}{ Fault conditions } \\
\hline Internal overpressure, $\mathrm{MPa}$ & 0.5 & C \\
\hline External overpressure, $\mathrm{MPa}$ & 0.2 & C \\
\hline Seismic, $\mathrm{g}$ & TBD & $A-C$ \\
\hline
\end{tabular}


exceed Level A criteria, which allow no loss of performance of the component. Emergency conditions must meet Level C criteria, which allow some yielding and may require inspection before returning the component to service.

The plasma disruption loads are due to inductive currents in the conducting structures as well as conductive or halo currents that flow between the plasma and the conducting structures. The magnitude and distribution of these currents are functions of vessel and in-vessel component design, electrical connectivity, and plasma conditions (e.g., halo temperature and width) and are very difficult to quantify. Experimental results from the tokamak experiment at General Atomics (DIII-D), the Joint European Torus (JET), C-MOD, and JT-60 indicate high halo currents with toroidal asymmetry up to a factor of $2[4]$.

A typical vertical displacement episode (VDE) disruption has several phases.

Drift phase-Vertical motion of the plasma induces toroidal currents opposing motion of plasma and a net vertical force on the structure.

Thermal quench-Diamagnetic flux change from beta collapse induces poloidal currents in structure and plasma halo; radial motion of plasma induces toroidal currents to oppose motion.

Current quench-Plasma current decay induces toroidal and poloidal currents in conducting structure and plasma halo; the halo currents interact directly with the structure.

This series of events produces a response in the structure that is highly dependent on the relative time constants of the conducting components and the plasma motion and current decay times. It produces a complex loading pattern with multiple force peaks.

To determine some worst-case loading envelopes for ITER, various simulations have been performed using the Tokamak Simulation Code (TSC) and the MAXFEA code. TSC is a numerical model of a free-boundary axisymmetric tokamak plasma that interacts self-consistently with nearby conductors [5]. TSC incorporates a model of a plasma halo with specified temperature and width that yields predictions of the magnitudes of poloidal halo currents and first wall pressures. The code has been used to successfully model disruptive episodes in the ASDEX-U, DIII-D, PBX-M, and Tokamak Fusion Test Reactor (TFTR) tokamaks. The latest TSC structural model indicating the various conducting surfaces and the electrical connections between components is shown in Fig. 2 . The MAXFEA [6] is also a free-boundary time evolution model of a plasma, but it simplifies the modeling of the conducting structure and plasma interaction.

These codes have been used extensively to model various types of ITER disruptions, including fast radial, vertical, slow VDE, and fast VDE. These disruption types are within the

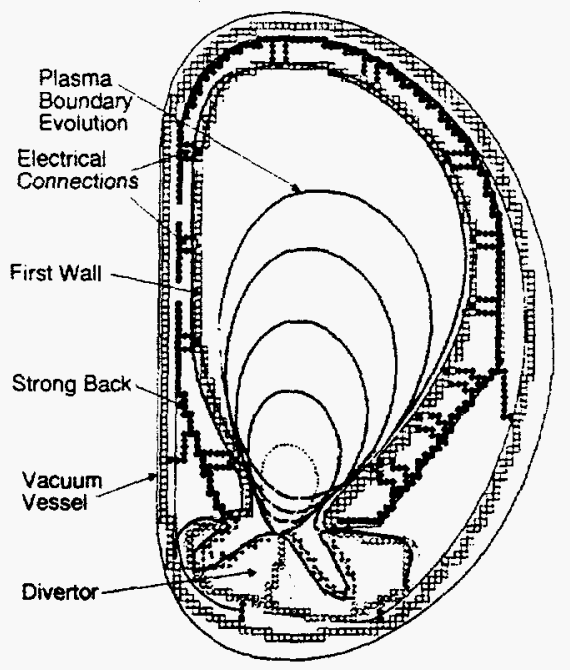

Fig. 2 Axisymmetric model of conducting structures for TSC disruption simulation.

parameters specified in the ITER General Design Requirements Document [7].

Table II compares the results of the simulations [8]. As shown, the plasma current decay rate and vertical drift vary considerably for the various simulations, as does the vertical force on the conducting components. The time evolution of these forces is shown in Fig. 3 for a "slow VDE" TSC disruption simulation. As expected, the peak pressure loads on the conducting surfaces also vary depending on the disruption type. Table III summarizes peak pressures for the first wall, divertor, vacuum vessel, and backplate for each of four types of disruptions. The vacuum vessel loads represent the total pressure on both facesheets of the double-wall structure and are relatively constant regardless of disruption type. This is due to the electromagnetic shielding provided by the in-vessel components. However, the pressures listed do not include the large traction forces on the sidewalls of the modules caused by radial currents; they exist because the modules are not electrically connected at the first wall.

\section{ANALYSIS MODELS}

Two global finite-element models have been used for this analysis, a simplified model for dynamic analysis and a more detailed model of the vacuum vessel for static and combined loading analysis [9].

To determine the dynamic structural response of the vacuum vessel and internal components to disruption loads, a model was constructed that includes an $18^{\circ}$ sector of the shieldblanket/backplate assembly and vertical supports, the vacuum vessel with port extensions, and the vacuum vessel vertical supports. To limit the size of the model, the double-wall vacuum vessel is represented by a single layer of composite shell elements. Loads were applied by mapping the axisymmetric loads from TSC directly onto the dynamic model 
Table II

Plasma Disruption Simulation Resuits

\begin{tabular}{|c|c|c|c|c|c|c|c|c|c|}
\hline \multirow[b]{2}{*}{ Simulation } & \multirow[b]{2}{*}{ Type } & \multirow{2}{*}{$\begin{array}{c}\text { I }_{\text {plasma }} \\
(\mathrm{MA})\end{array}$} & \multirow{2}{*}{$\begin{array}{l}<d \mathrm{Ip} / \mathrm{d} t\rangle \\
(\mathrm{MA} / \mathrm{ms})\end{array}$} & \multirow{2}{*}{$\begin{array}{c}\Delta Z \\
\text { (drift) } \\
(\mathrm{m})\end{array}$} & \multirow{2}{*}{$\begin{array}{l}\text { Ihalo }^{*} \\
\text { (MA) }\end{array}$} & \multirow{2}{*}{$\begin{array}{c}\text { I }_{\text {poloidal }} \\
\text { in structure } \\
\text { (MA) }\end{array}$} & \multicolumn{3}{|c|}{$\begin{array}{l}\text { Vertical force } \\
\text { (MN) }\end{array}$} \\
\hline & & & & & & & $V V+D i v$ & $F W+B P$ & $\begin{array}{l}\text { Maximum } \\
\text { total }\end{array}$ \\
\hline TSC $940408 \mathrm{H}$ & Slow VDE & 25 & $\sim-0.06$ & -1.6 & 6.1 & 6.7 & -122 & -133 & -188 \\
\hline MAXFEA S 82 MD 10 94-05-26 W 1 & Slow VDE & 24 & --0.04 & -1.6 & 7.2 & & -29 & -116 & -157 \\
\hline TSC 950114D & $\begin{array}{l}\text { Fast rad } \\
\text { Case I }\end{array}$ & 24 & -2.1 & 0 & 0 & 3.3 & & & -4 \\
\hline TSC 950407E & $\begin{array}{l}\text { Vertical } \\
\text { Case II }\end{array}$ & 24 & -0.2 & -0.2 & 0 & $<3.3$ & & & -11 \\
\hline TSC $950315 \mathrm{H}$ & $\begin{array}{l}\text { Slow VDE } \\
\text { Case III }\end{array}$ & 24 & -0.06 & -1.23 & 4.6 & $<3.3$ & -74 & -84 & -113 \\
\hline MAXFEA S 73 MD 12 95-04-06 W1.1 & Slow VDE & 21 & -0.055 & & 7.0 & & -51 & -99 & -147 \\
\hline TSC $950428 \mathrm{G}$ & $\begin{array}{l}\text { Fast VDE } \\
\text { Case IV }\end{array}$ & 24 & -2.1 & -1.23 & 3.5 & & -17 & -67 & -60 \\
\hline
\end{tabular}

*I halo = peak toroidal current in plasma halo.

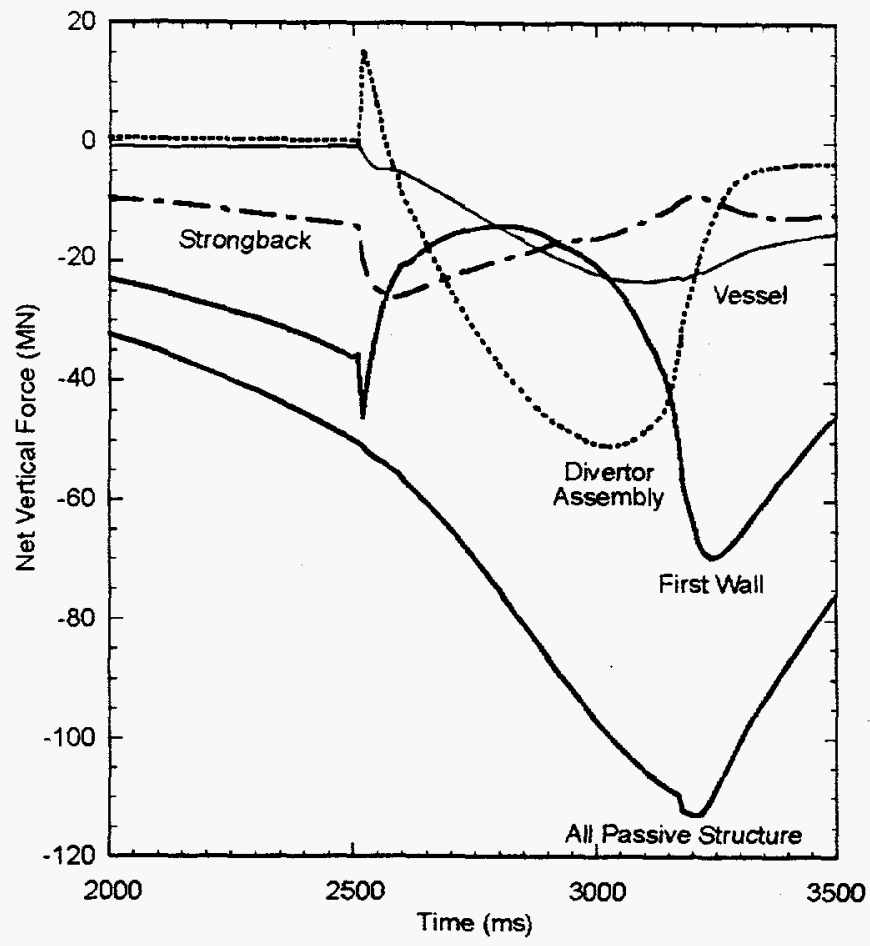

Fig. 3 Time evolution of vertical forces in conducting structures for slow VDE, TSC case $950315 \mathrm{H}$.

Table III

Variation of Peak Pressures on Conducting Surfaces for Four TSC Plasma Disruption Simulations [8]

\begin{tabular}{lcccc}
\hline \multirow{2}{*}{$\begin{array}{c}\text { Conducting } \\
\text { surface }\end{array}$} & \multicolumn{5}{c}{ Peak pressure on surfaces of conducting components } \\
& $\begin{array}{c}\text { Case I } \\
\text { fast radial }\end{array}$ & $\begin{array}{c}\text { Case II } \\
\text { vertical }\end{array}$ & $\begin{array}{c}\text { Case III } \\
\text { slow VDE }\end{array}$ & $\begin{array}{c}\text { Case IV } \\
\text { fast VDE }\end{array}$ \\
\cline { 2 - 5 } & 0.90 & 0.72 & 0.70 & 0.95 \\
First wall & 0.10 & 0.35 & 0.29 & 0.29 \\
Backplate & 0.78 & 0.77 & 0.65 & 0.55 \\
Divertor & 0.30 & 0.30 & 0.27 & 0.27 \\
Vacuum vessel & & & & \\
\hline
\end{tabular}

nodes. Loads from both slow VDE and fast VDE events were applied. To evaluate nonsymmetric loading, a static cyclic symmetry solution was used that allowed each sector to be loaded differently. The nonsymmetric halo currents were approximated by a $(1-\cos 0)$ distribution for the loads because of the halo currents. The other loads were symmetrically applied.

For static analysis of the vacuum vessel only, a more detailed model was developed that includes both the inner and outer facesheets, the interconnecting ribs, the vertical supports, the reinforcement at the blanket support locations, and the divertor rails. This model was loaded by applying peak reactions at the blanket supports in combination with loads on the divertor rails and vacuum vessel facesheets.

\section{ANALYSIS RESULTS}

\section{Dynamic Analysis}

The peak deflections of the vacuum vessel and the blanket and shield and the reactions at the blanket supports and the vessel supports are listed in Table IV and depicted graphically in Figs. 4 and 5. The maximum tresca "stress" is also listed in Table IV, but it must be noted that this is listed for comparison only, because the model is not detailed enough to yield accurate peak stress values. The dynamic response of the vacuum vessel to the disruption loads indicates a relatively low dynamic multiplication factor on stress for the "slow" VDE, but a much higher magnification factor for the "fast" VDE.

\section{Static Analysis and Combined Loads}

The results of the static analysis of the vacuum vessel with combined loads are listed in Table V. The peak stresses occur at the intersection of the divertor duct and the torus and around the vertical support brackets. These stresses are more 
Table IV

Comparison of Static and Dynamic Results of Simplified Model Analysis with Symmetrical Disruption Loads

\begin{tabular}{|c|c|c|c|c|}
\hline \multirow{2}{*}{$\begin{array}{l}\text { Parameter } \\
\text { Analysis type }\end{array}$} & \multicolumn{2}{|c|}{ Slow VDE } & \multicolumn{2}{|c|}{ Fast VDE } \\
\hline & Static & Dynamic & Static & Dynamic \\
\hline VV deflection, mm & 9.8 & 13.6 & 9.3 & 12.1 \\
\hline $\begin{array}{l}\text { Blanket and shield } \\
\text { assembly deflection, } \\
\mathrm{Imm}\end{array}$ & 7.9 & 15.1 & 16.9 & 26.0 \\
\hline $\begin{array}{l}\text { Inboard blanket and } \\
\text { shield assembly sup- } \\
\text { port vertical reactions, } \\
\text { MN (total for } 40 \text { ) }\end{array}$ & 67.1 & 77.1 & 19.1 & 52.2 \\
\hline $\begin{array}{l}\text { Outboard blanket and } \\
\text { shield assembly sup- } \\
\text { port vertical reactions, } \\
\text { MN (total for } 40 \text { ) }\end{array}$ & 76.2 & 92.1 & 48.1 & 129.3 \\
\hline $\begin{array}{l}\text { Vacuum vessel vertical } \\
\text { support reactions, MN } \\
\text { (total for } 20 \text { ) }\end{array}$ & 293.1 & 306.1 & 184.3 & 235.1 \\
\hline $\begin{array}{l}\text { Maximum tresca } \\
\text { "stress" in VV torus, } \\
\mathrm{MPa}\end{array}$ & 100 & 112 & 72 & 105 \\
\hline
\end{tabular}
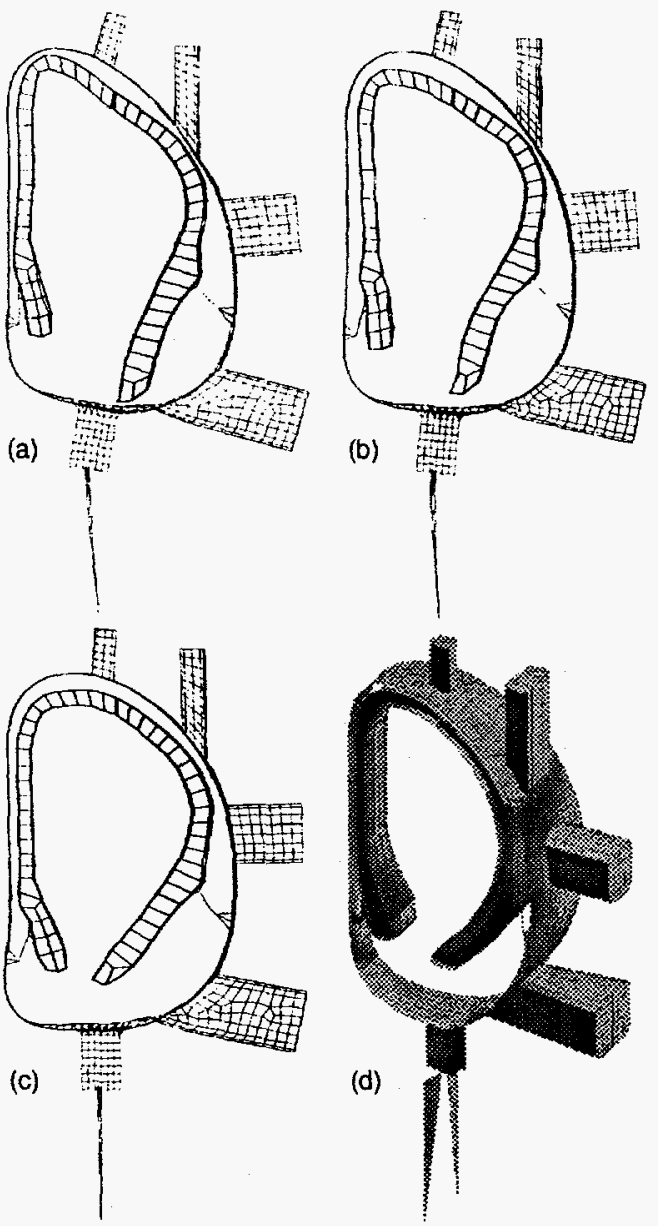

Fig. 4 Time evolution of deformations for slow VDE.

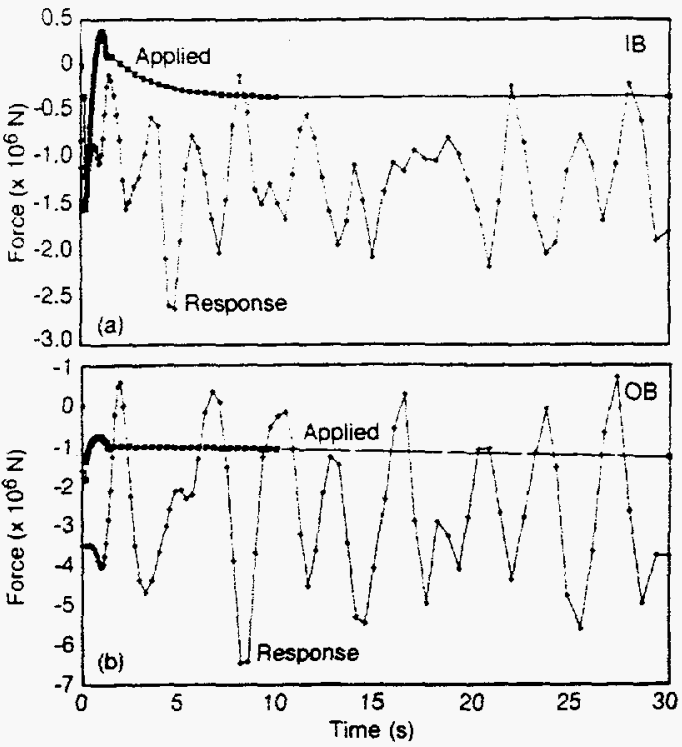

Fig. 5 Time evolution of inboard and outboard blanket support reactions for fast VDE.

Table V

Maximum Stress in Vacuum Vessel from Statically Applied Loads Compared with Allowable Stress

\begin{tabular}{|c|c|c|c|c|}
\hline \multirow[b]{2}{*}{ Load case } & \multicolumn{2}{|c|}{$\begin{array}{l}\text { Maximum calculated } \\
\text { vessel stress (MPa) }\end{array}$} & \multicolumn{2}{|c|}{$\begin{array}{c}\text { Allowable stress (MPa) } \\
@ 200^{\circ} \mathrm{C}(\mathrm{SF}) \\
\end{array}$} \\
\hline & $\begin{array}{l}\text { Maximum } \\
\text { membrane }\end{array}$ & $\begin{array}{c}\text { Maximum } \\
\text { membrane + } \\
\text { bending }\end{array}$ & $\begin{array}{l}\text { Primary } \\
\text { membrane }\end{array}$ & $\begin{array}{l}\text { Primary } \\
\text { membrane + } \\
\text { bending }\end{array}$ \\
\hline Normal operation & 118 & 133 & $\begin{array}{c}131 \\
(1.1)\end{array}$ & $\begin{array}{r}197 \\
(1.5)\end{array}$ \\
\hline $\begin{array}{l}\text { Operation with } \\
\text { slow VDE }\end{array}$ & 117 & 152 & $\begin{array}{c}131 \\
(1.1)\end{array}$ & $\begin{array}{r}197 \\
(1.3)\end{array}$ \\
\hline $\begin{array}{l}\text { Operation/ with } \\
\text { estimated } \\
\text { correction } b\end{array}$ & 187 & 193 & $\begin{array}{c}131 \\
(0.7)\end{array}$ & $\begin{array}{c}197 \\
(1.0)\end{array}$ \\
\hline $\begin{array}{l}\text { Off-normal } \\
\text { operation with } \\
0.5-\mathrm{MPa} \text { internal } \\
\text { pressure }\end{array}$ & 142 & 183 & $\begin{array}{c}157 \\
(1.1)\end{array}$ & $\begin{array}{r}236 \\
(1.3)\end{array}$ \\
\hline
\end{tabular}

aSymmetrically applied.

$b_{2} \times$ slow VDE loads.

realistic than the simplified model, but are still not completely reliable for peak values because the mesh is not fine enough. As shown in the table, the ratio of calculated stress to actual stress is very close to unity for symmetrically applied loads and is significantly less than unity if a factor is applied to account for dynamic effects and nonaxisymmetric halo forces. This result has prompted the project to investigate options for reducing the peak stresses. Fig. 6 illustrates the deflected shape and peak stress locations for the "slow" VDE loading condition. 

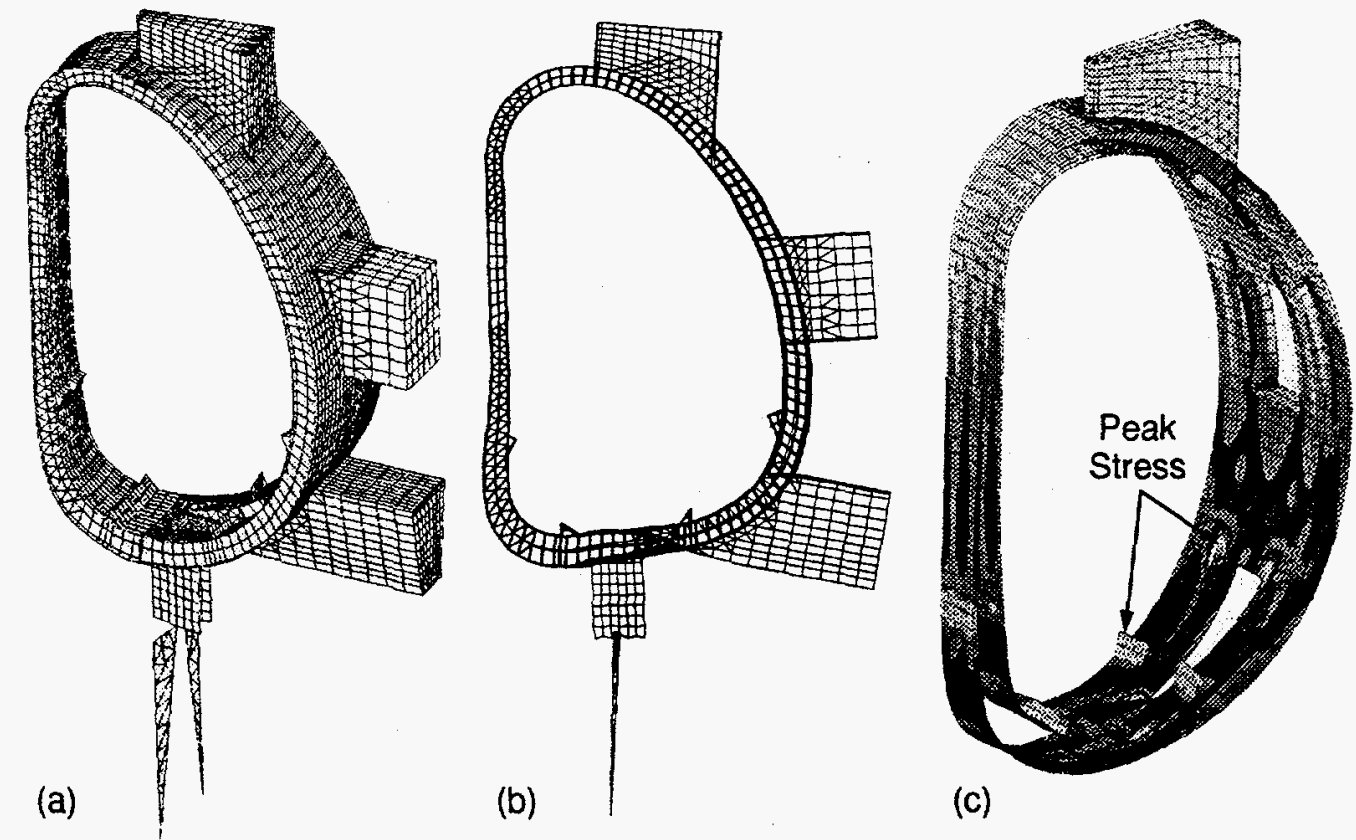

(c)

Fig. 6 Analysis model, deformations, and peak stress for vacuum vessel subject to static application of slow VDE loads.

Preliminary analysis was performed using the cyclic symmetry model for nonaxisymmetric halo current loads for the TSC case $940408 \mathrm{H}$, assuming a (1-cos 0 ) distribution. Results indicate very large lateral motion (up to $90 \mathrm{~mm}$ ) and high forces in the supports (up to $34 \mathrm{MN}$ vertical and $10 \mathrm{MN}$ lateral in a single support). This may be a conservative analysis approach, because the halo current loading has been observed to rotate toroidally at a fairly high frequency. The inertia of the system would tend to push the dynamic response of the structure more toward a symmetric condition.

\section{CONCLUSIONS AND FUTURE WORK}

The evaluation of disruption loads and the resulting structural response of the vacuum vessel and in-vessel components are complicated problems that must be approached in stages. The present stage includes the simulation of a representative set of plasma disruption scenarios and a simplified application of the calculated loads to linear dynamic and static models. The resulting stress and deflection information is being used to modify the vacuum vessel design and evaluate the blanket/shield supports and the vacuum vessel supports. Additional analysis is needed to more accurately evaluate nonsymmetric loading from halo currents and seismic events.

\section{REFERENCES}

[1] ITER Interim Design and Cost Report, TTER Joint Central Team, July 1995.

[2] ITER System Design Description, ITER Joint Central Team, July 1995.

[3] ITER Interim Structural Design Criteria, Internal Draft 3, July 1995, unpublished.

[4] "Disruption/VDE Characterization Workshop/Technical Meeting," Garching ITER Joint Work Site, Information as of Feb. 2, 1995, unpublished. [5] S. Jardin et al., "Dynamic Modeling of Transport and Position Control of Tokamaks," J. Comp. Physics 66, 481 (1986).

[6] MAXFEA, P. Barabaschi, ITER Joint Central Team.

[7] ITER General Design Requirements Document, ITER S 10 GDRED 2 95-02-10 F1.0, ITER JCT, San Diego, June 6, 1995.

[8] R. Sayer, "TSC Disruption Simulations for the ITER 24 MA Design," ITER Report ITER/US/95/INV-VV-01, Sept. 30, 1995.

[9] B. Riemer et al., "ITER Vacuum Vessel Structural Analysis," these proceedings. 